See Article page 1438.

\section{Commentary: Proceed with caution}

\author{
Corinne Tan, MD, and Charles B. Huddleston, MD
}

The reversed Potts shunt was first promoted for palliation of pulmonary hypertension by Blanc and colleagues in 2004 . $^{1}$ Before this, atrial septostomy had been the mainstay of palliation, albeit at the expense of optimal oxygen delivery to the coronary and cerebral vascular bed. Since then, the reversed Potts shunt has evolved to include a graft when needed, and has been shown to be an effective means of improving right ventricular (RV) function, quality of life, and transplant-free survival in patients with recalcitrant pulmonary arterial hypertension. ${ }^{2}$ Although traditionally done via a left thoracotomy, ${ }^{3}$ transcatheter experiences have been described. ${ }^{4}$

Rosenzweig and colleagues ${ }^{5}$ report a small series of 5 patients (median weight, $46 \mathrm{~kg}$ ) with suprasystemic pulmonary artery pressures, severe RV dysfunction, and World Health Organization functional class IV symptoms who underwent creation of a unidirectional valved reverse Potts shunt via median sternotomy and cardiopulmonary bypass (CPB) using a 12-mm Contegra valved conduit (Medtronic, Minneapolis, Minn). The purported advantage of this over the more conventional reversed Potts shunt is prevention of a left to right shunt in the setting of an already hypertensive pulmonary bed. At a median follow-up time of 6 months, all 5 patients were alive and had an improvement in RV function and World Health Organization functional class with no major complications. In fact, 3 of 5 patients previously listed for lung transplantation were taken off active listing.

Whereas we applaud the authors' efforts in this high risk group of patients, one should be mindful of the risks of

\footnotetext{
From the Division of Cardiothoracic Surgery, Saint Louis University School of Medicine and Cardinal Glennon Children's Hospital, St Louis, Mo.

Disclosures: The authors reported no conflicts of interest.

The Journal policy requires editors and reviewers to disclose conflicts of interest and to decline handling or reviewing manuscripts for which they may have a conflict of interest. The editors and reviewers of this article have no conflicts of interest.

Received for publication Dec 19, 2020; revisions received Dec 19, 2020; accepted for publication Dec 21, 2020; available ahead of print December 26, 2020.

Address for reprints: Charles B. Huddleston, MD, Division of Cardiothoracic Surgery, Saint Louis University School of Medicine and Cardinal Glennon Children's Hospital, 1465 S Grand Blvd, Suite 5727 Glennon Hall, St Louis, MO 63104 (E-mail: Charles.Huddleston@ health.slu.edu).

J Thorac Cardiovasc Surg 2021;161:1451-2

$0022-5223 / \$ 36.00$

Copyright (c) 2020 by The American Association for Thoracic Surgery

https://doi.org/10.1016/j.jtcvs.2020.12.082
}

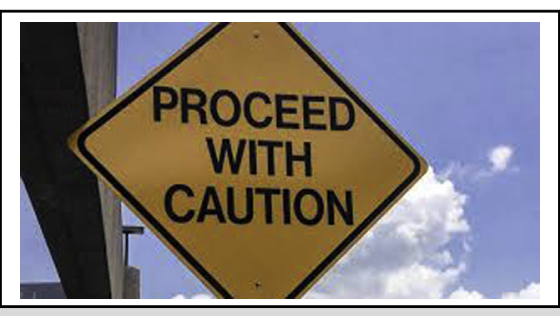

Proceed with caution-always a good idea when navigating dangerous roadways.

\section{CENTRAL MESSAGE \\ A reverse Potts shunt with a valved conduit for pulmonary hypertension is feasible. Whether there is any advantage over the nonvalved Potts shunt is unclear.}

attempting to duplicate their technique. Patients with severe pulmonary hypertension and RV dysfunction are often critically ill and performing any procedure on CPB is a big undertaking with the potential for a rocky postoperative course as reflected in the almost 1-month median hospital length of stay and the use of extracorporeal membrane oxygenation (ECMO) in 4 out of 5 patients for a median of 5 days. Although a unidirectional valved conduit for a reverse Potts shunt seems logical, the durability of the Contegra valve in this setting is unclear; if (when) it becomes incompetent there would be little advantage of this procedure over a nonvalved Potts shunt, which is generally performed without CPB, without postoperative ECMO support, and short hospital length of stay.

Longer follow-up, as pointed out by the authors, would be valuable to evaluate not only the integrity of the valved conduit, but also the influence on clinical outcomes. Without question, these are outstanding results in a very high risk group of 5 patients. Having said that, it is a bit difficult to endorse an operation with an $80 \%$ incidence of postoperative ECMO and a 1 month hospital stay. We recommend proceeding with caution!

\section{References}

1. Blanc J, Vouhe P, Bonnet D. Potts shunt in patients with pulmonary hypertension. N Engl J Med. 2004;350:623.

2. Aggarwal M, Grady RM, Choudhry S, Anwar S, Eghtesady P, Singh GK. Potts shunt improves right ventricular function and coupling with pulmonary circulation in children with suprasystemic pulmonary arterial hypertension. Circ Cardiovasc Imaging. 2018;11:e007964.

3. Eghtesady P. Potts shunt for children with severe pulmonary hypertension. Operativ Tech Thorac Cardiovasc Surg. 2015;20:293-305. 
4. Esch JJ, Shah PB, Cockrill BA, Farber HW, Landzberg MJ, Mehra MR, et al, Transcatheter Potts shunt creation in patients with severe pulmonary arterial hypertension: initial clinical experience. J Heart Lung Transplant. 2013; $32: 381-7$.
5. Rosenzweig EB, Ankola A, Krishnan U, Middlesworth W, Bacha E, Bacchetta M. A novel unidirectional-valved shunt approach for end-stage pulmonary arterial hypertension: early experience in adolescents and adults. J Thorac Cardiovasc Surg. 2021;161:1438-46.e2. 